\title{
Microbiological Quality of Kachumbari, a Raw Vegetable Salad Popularly Served Alongside Roast Meat in Kenya
}

\author{
Kenneth M. Mbae (D), Mercy K. Ndwiga, and Fredrick G. Kiruki \\ Department of Food Science, Meru University of Science and Technology, P.O. Box 972, Meru 60200, Kenya \\ Correspondence should be addressed to Kenneth M. Mbae; kmbae@must.ac.ke
}

Received 8 March 2018; Accepted 17 April 2018; Published 8 May 2018

Academic Editor: Jordi Rovira

Copyright (C) 2018 Kenneth M. Mbae et al. This is an open access article distributed under the Creative Commons Attribution License, which permits unrestricted use, distribution, and reproduction in any medium, provided the original work is properly cited.

\begin{abstract}
Raw salads are regularly implicated in food-borne disease outbreaks globally. Consumption of kachumbari, a raw vegetable salad, alongside roast meat is widespread in Kenya. The aim of this study was to evaluate the bacteriological quality of kachumbari samples $(n=39)$ collected from a cross section of roasted meat eateries in Kenya. The United Kingdom's Health Protection Agency guidelines were used to infer safety of the salads due to lack of local criteria for microbiological safety of ready-to-eat fresh produce placed in the market. Based on Escherichia coli counts, 14 (35.9\%) of the samples were of satisfactory microbial quality $(<20 \mathrm{CFU} / \mathrm{g}), 7$ (17.9\%) in the borderline $\left(20-10^{2} \mathrm{CFU} / \mathrm{g}\right)$, and $18(46.2 \%)$ unsatisfactory $\left(>10^{2} \mathrm{CFU} / \mathrm{g}\right)$. All samples examined for staphylococci had counts falling within the borderline range $\left(20-10^{4} \mathrm{CFU} / \mathrm{g}\right)$. Collectively, $3(7.7 \%)$ of the sampled salads were classified as potentially harmful to health and/or unfit for human consumption due to the presumptive presence of 2 (5.1\%) Campylobacter spp. and $1(2.6 \%)$ E. coli O157. Salmonella was not detected in any of the samples. The presence of hygiene indicator microorganisms and pathogens demonstrates that kachumbari salads present a public health risk.
\end{abstract}

\section{Introduction}

A ready-to-eat raw vegetable salad locally referred to as kachumbari is widely prepared at home and in food outlets around Kenya. Its common fresh ingredients include tomatoes and red bulb onions [1]. The recipe could vary to include bell peppers, coriander, and hot green/red chilies. Occasionally, freshly squeezed lemon juice or vinegar is added to enhance the flavour. The vegetables are normally washed, chopped into small pieces, and mixed to yield the salad (Figure 1). Serving kachumbari as an accompaniment to nyama choma (roast meat) is a popular cultural practice in Kenya [2]. This combination is offered in a cross section of top-class to low-end roast meat eateries that are ubiquitous in urban centres and the countryside and is popular among locals and tourists visiting the country.

Disease occurrences associated with fresh fruits and vegetables are increasingly becoming a global public health concern $[3,4]$. Several recorded food-borne disease outbreaks in the world have been attributed to minimally processed fresh produce. For instance, in 2011, a Shiga toxinproducing Escherichia coli outbreak in Europe was linked to fenugreek sprouts [5]. In 2013, there was a multistate outbreak of Shiga toxin-producing E. coli O157:H7 linked to ready-to-eat salads in the USA [6]. Minimally processed vegetables and fruits are the leading causes of food-borne disease outbreaks in the USA [7]. In the USA and Europe, the Centres for Disease Control and Prevention and European Food Safety Authority, respectively, investigate, track, and preserve data on food-borne disease outbreaks $[5,6]$. Kenya lacks such elaborate fact-finding mechanisms; hence, precise data relating to outbreaks associated with foods including fresh produce are difficult to obtain. However, perturbing trends in North America and Europe, which are regions with stringent food safety regulations, validate the concern. The most important pathogenic enteric bacteria contaminants of fresh cut produce include Campylobacter spp., E. coli, Salmonella spp., and Shigella spp. [8]. Other bacteria of concern are Listeria monocytogenes, Staphylococcus aureus, Yersinia enterocolitica, and Aeromonas spp., depending on product 


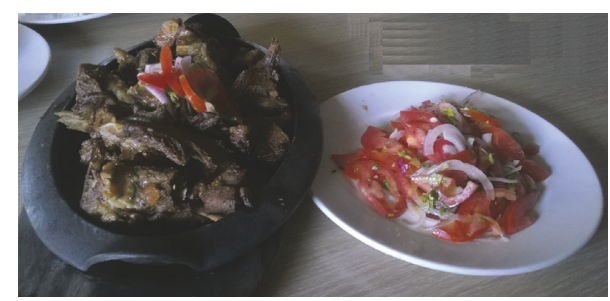

FIgURE 1: Kachumbari salad served alongside roast meat.

handling conditions during preparation and storage. Sporeforming bacteria of Bacillus spp. and Clostridium spp. can also persist where fresh cut produce is held in modified atmosphere packs, which can favour germination of spores and growth of vegetative cells $[8,9]$.

Raw vegetables salads are microbiologically risky foods since they are eaten uncooked [8]. This necessitates enforcement of strict sanitary practices from field to fork because there is no single step that can ensure complete elimination of potentially pathogenic microorganisms from their ingredients as compared to cooked meals. In Kenya, consumer protection against unwholesome food is provided for by several legislations. They include the Food, Drugs and Chemical Substances Act, Chapter 254; the Public Health Act, Chapter 242; and the Meat Control Act, Chapter 316, of the Kenyan laws [10]. The regulations are enforced by the Department of Public Health under the Ministry of Public Health and Sanitation. Additionally, the Kenya Bureau of Standards (KEBS) formulates and enforces specific product standards for processed foods. There exist no guidelines governing the microbiological quality of prepared ready-to-eat raw foods served to consumers in Kenyan public eateries. A number of studies carried out in the country have revealed the presence of pathogenic enteric microorganisms in raw salads, in cooked foods, and on food-handling personnel and also documented poor food-handling practices in food outlets [11-16]. None of the encountered studies have specifically focused on kachumbari in roast meat eateries. Preparation of kachumbari in a meat-handling environment is potentially hazardous since raw meats are widely recognized as major sources of enteric pathogens $[17,18]$. The meats on offer at nyama choma outlets include chevon (goat meat), beef, lamb, chicken, and pork.

In view of the aforementioned, the current study was aimed at evaluating the microbial quality of kachumbari from a cross section of roasted meat eateries by assaying for hygiene indicator microo rganisms and food-borne pathogens occasionally associated with fresh cut vegetables. The ultimate target is sensitizing food handlers, consumers, and food safety enforcement authorities about the health risk posed by kachumbari.

\section{Materials and Methods}

2.1. Sampling. The study sites comprised 5 towns located in the Mount Kenya region within $80 \mathrm{~km}$ radius from the Meru town, which is located $224 \mathrm{~km}$ to the northeast of the Kenya's capital, Nairobi (Figure 2). Akin to many other towns, roast meat eateries are popular.

Three roast meat eateries offering kachumbari as part of the menu were randomly selected in each town. Between 2014 and 2015, 3 samples per eatery were procured at 1-week interval except in Maua town to yield a total of 39 vegetable salad samples, that is, Meru $(n=9)$, Chuka $(n=9)$, Nanyuki $(n=9)$, Isiolo $(n=9)$, and Maua $(n=3)$. The salads were put in clear polythene bags as customarily dispensed by the vendors for takeaway packs. The samples were transported to the laboratory in a cool box with frozen gel packs and analyzed on the same day. Additional information collected during field sampling included the animal source of meats served by individual outlets and inclusion of lemon juice or vinegar in the salads. Ingredients in the samples were also noted.

2.2. Microbial Analysis. Microbial determinations were carried out according to the International Organization for Standardization (ISO) methods, namely, beta-glucuronidasepositive E. coli: ISO 16649-2:2001, coagulase-positive staphylococci: ISO 6888-2:1999, E. coli O157: ISO 16654:2001, Salmonella spp.: ISO 6579:2002, and Campylobacter spp.: ISO 10272-1:2006 [19-23]. Briefly, $10 \mathrm{~g}$ of each vegetable salad sample was aseptically weighed into a sterile Pulsifier ${ }^{\circledR}$ plastic bag (Microgen Bioproducts Ltd., UK), and $90 \mathrm{ml}$ of sterile Maximum Recovery Diluent (MRD) (HiMedia Laboratories, India) was added to make a $1: 10$ dilution. The bag was placed in the Pulsifier (Microgen Bioproducts Ltd., UK) and treated for 30 seconds [24]. Serial dilutions of the suspension were made in MRD and analyzed for beta-glucuronidase-positive E. coli and coagulase-positive staphylococci using the pour plate method by dispersing $1 \mathrm{ml}$ of dilutions in Tryptone Bile X-Glucuronide Medium (HiMedia Laboratories, India) and Rabbit Plasma Fibrinogen Agar (HiMedia Laboratories, India), respectively, followed by incubation and enumeration as recommended in the standard protocols. For detection of E. coli O157, $25 \mathrm{~g}$ of each sample was aseptically weighed and placed into a sterile Pulsifier plastic bag, $225 \mathrm{~mL}$ of sterile Modified Soyabean Bile Broth supplemented with novobiocin at $20 \mathrm{mg} / \mathrm{L}$ (HiMedia Laboratories, India) was added, and an enrichment homogenate was made by treating with the Pulsifier for 30 seconds. The mixture was incubated and subcultured onto Tellurite Cefixime Sorbitol MacConkey Agar (HiMedia Laboratories, India) and HiCrome MacConkey Sorbitol Agar (HiMedia Laboratories, India). Twentyfive grams of test portions for detection of Salmonella were preenriched in Buffered Peptone Water (ISO) (HiMedia Laboratories, India) supplemented with potassium sulphite $0.5 \% w / v$ (final concentration) for all samples containing onions to reduce natural bactericidal properties. They were then enriched in Rappaport Vassiladis Soyabean Meal Broth and Muller-Kauffmann Tetrathionate-Novobiocin Broth (HiMedia Laboratories, India) and subcultured onto XyloseLysine-Deoxycholate Agar and Salmonella Differential HiVeg Agar (HiMedia Laboratories, India). Finally, a $25 \mathrm{~g}$ of test portion for Campylobacter was enriched in Blood Free Campylobacter Broth (HiMedia Laboratories, India) and 


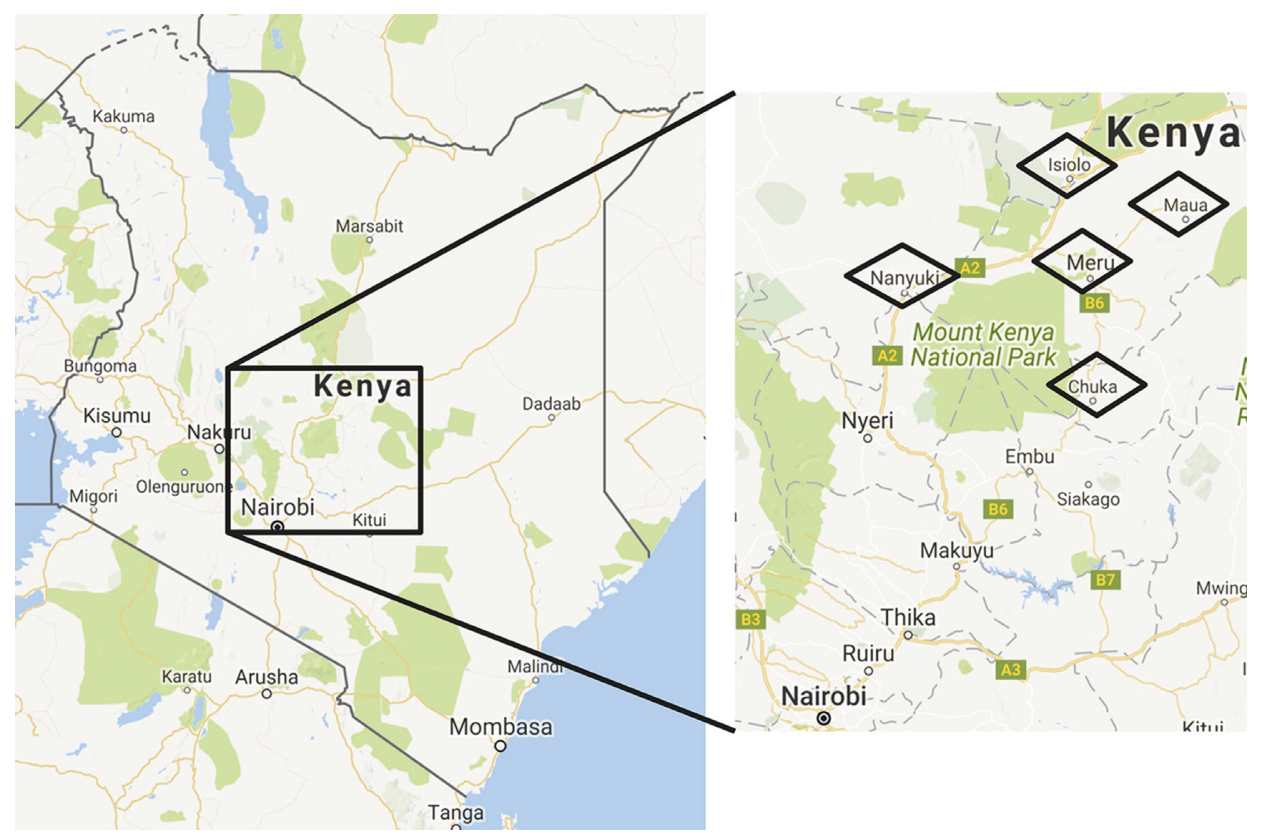

FIgURE 2: Map showing towns where raw vegetable salad samples were sourced.

subcultured onto Blood Free Campylobacter Selectivity Agar and Karmali Campylobacter Agar (HiMedia Laboratories, India). Microaerophillic condition in a 3.5-litre incubation jar was generated using CampyGen CN0035A sachets (Oxoid Ltd., UK).

Presumptive confirmation of suspect colonies of E. coli O157, Salmonella, and Campylobacter was done using Microgen E coli 0157-CEM44 Latex Kit, Microgen SalmonellaCEM42 Latex Kit, and Microgen Campylobacter-CEM46 Latex Kit (Microgen Bioproducts Ltd., UK), respectively, as per the manufacturer's instructions.

2.3. pH Measurement. The $\mathrm{pH}$ was taken in the salad exudate after aseptically drawing samples for microbial analysis and allowing them to stabilize at room temperature. The $\mathrm{pH}$ meter (Model pH 211, Hanna Instruments, Italy) equipped with an $\mathrm{HI} 1131 \mathrm{~B}$ glass body combination refillable $\mathrm{pH}$ electrode and an HI 7669/2W temperature probe for automatic temperature compensation was used according to the manufacturer's instructions. Briefly, a two-point calibration with $\mathrm{pH} 4.01$ and $\mathrm{pH} 7.01$ buffer solutions was performed, the salad exudate was decanted into a plastic $50 \mathrm{ml}$ beaker, $\mathrm{pH}$ electrode and temperature probe tips submerged approximately $4 \mathrm{~cm}$ into the liquid and were allowed to stabilize, and the reading was taken. Deionized water was used to rinse the probes between the measurements.

2.4. Data Analysis. Microsoft Excel 2010 with data analysis add-ins was used to compute, summarize descriptive statistics, and generate graphical illustrations. Correlation analysis was done to establish the strength of relationship between $\mathrm{pH}$ of the samples and E. coli counts. Categorized microbial data were compared against the UK Health Protection Agency Guidelines for Assessing the Microbiological

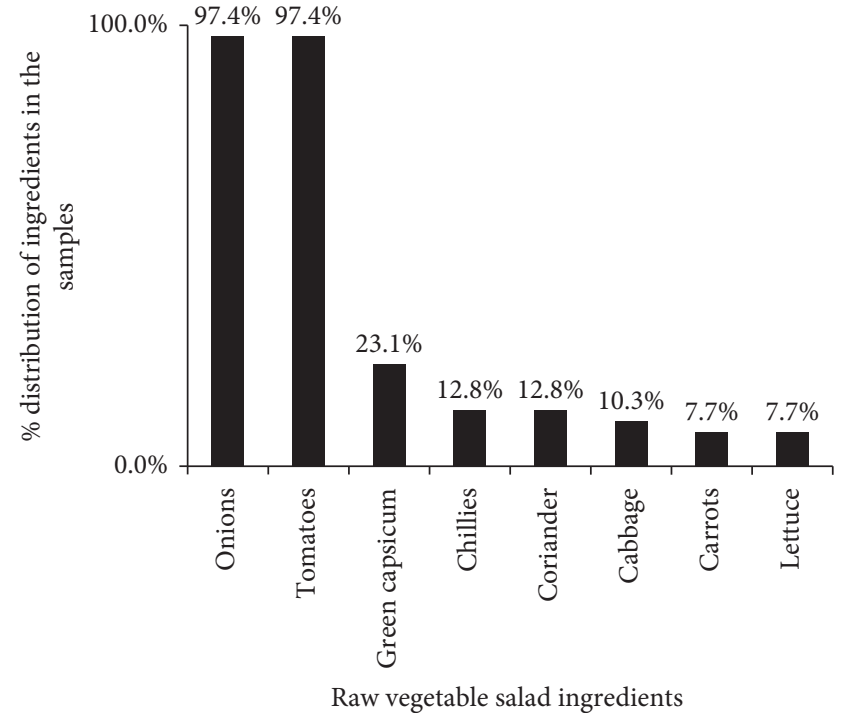

FIgURE 3: Vegetables used in kachumbari raw salads served by roast meat eateries $(n=39)$.

Safety of Ready-to-Eat Foods [25], and deductions on the microbial quality and safety of the salads were tabulated.

\section{Results}

Roasted goat meat was served by all sampled eateries (15, $100 \%)$, followed by beef $(14,93.3 \%)$ and chicken $(10,66.7 \%)$. Tomatoes and onions were virtually present in all the vegetable salads. Other ingredients used to a lesser extent included green capsicum, chilies, coriander leaves, cabbage, lettuce, and carrots (Figure 3). It was also noted that ingredients used by the specific eateries varied from one sampling interval to the next. One eatery was recorded to 
TABLE 1: Level of contamination by hygiene indicator microorganisms in raw vegetables salads served by roast meat eateries.

\begin{tabular}{lccc}
\hline Hygiene indicator microorganisms & CFU/g (interpretation) & \% of samples $(n=39)$ & Samples' pH interval \\
\hline Beta-glucuronidase-positive & $<20$ (satisfactory) & $14(35.9 \%)$ & $3.95-4.53$ \\
Escherichia coli & $20-\leq 10^{2}$ (borderline) & $18(4.9 \%)$ & $3.89-4.81$ \\
\hline \multirow{2}{*}{ Staphylococcus aureus and other } & $>10^{2}$ (unsatisfactory) & $0 \%$ & $3.45-4.62$ \\
coagulase-positive staphylococci & $20-\leq 10^{4}$ (borderline) & $39(100 \%)$ & $0 \%$ \\
\hline
\end{tabular}

Satisfactory: suitable for human consumption; borderline: moderate microbiological risk; unsatisfactory: unsuitable for human consumption as per the Health Protection Agency Guidelines for Assessing the Microbiological Safety of Ready-to-Eat Food [25].

TABLE 2: Presumptive positive incidence of food-borne pathogens in the raw vegetables salad samples from roast meat eateries $(n=39)$.

\begin{tabular}{lc}
\hline Pathogen & $\begin{array}{c}\text { Presence in 25 g (unsatisfactory/potentially } \\
\text { injurious to health and/or unfit for human } \\
\text { consumption) }[25]\end{array}$ \\
\hline E. coli O157 & $1(2.6 \%)$ \\
Salmonella spp. & $\mathrm{ND}$ \\
Campylobacter spp. & $2(5.1 \%)$ \\
\hline
\end{tabular}

always incorporate lemon juice in the raw salad, while another occasionally put vinegar.

Levels of contamination with hygiene indicators are presented in Table 1. Categorization into satisfactory, borderline, and unsatisfactory classes was done according to the UK Health Protection Agency Guidelines for Assessing the Microbiological Safety of Ready-to-Eat Foods 2009 as indicated in the table. In regard to E. coli contamination, 25 (64.1\%) samples fell in the unsatisfactory and borderline categories. All samples evaluated for coagulase-positive staphylococci had counts falling within the borderline range. The $\mathrm{pH}$ of the salads ranged between 3.45 and 4.81, with $10(25.6 \%)$ of the samples having a $\mathrm{pH} \geq 4.5$. All satisfactory samples fell below the $\mathrm{pH} 4.53$. However, borderline and unsatisfactory salads were encountered across the entire $\mathrm{pH}$ interval (Table 1). There was a weak positive correlation between $\mathrm{pH}$ and E. coli counts $(r=+0.21)$, within the recorded $\mathrm{pH}$ range of the salad. High E. coli counts were scattered around the upper $\mathrm{pH}$.

Results of the presumptive presence of pathogenic foodborne enteric microorganisms are presented in Table 2. Collectively, 3 (7.7\%) of the sampled salads were classified as potentially harmful to health and/or unfit for human consumption due to the presumptive presence of the thermotolerant Campylobacter spp. and E. coli O157. There was no detection overlap between the samples that presumptively tested positive for either of the pathogens. Salmonella spp. was not detected in any of the kachumbari.

\section{Discussion}

With respect to available published information, this is the first report in Kenya specifically evaluating the microbial quality of kachumbari using hygiene indicator microorganisms and common enteric pathogenic microorganisms that have been associated with disease outbreaks arising from consumption of fresh produce. Overall, our results point to poor sanitary practices as indicated by high levels of E. coli. Contamination and carryover to the final salads could have arisen from poor field sanitation, unhygienic practices at harvesting, transport, and marketing stages, absence of surface decontamination, and cross-contamination at eateries. The high count of coagulase-positive Staphylococcus corroborates the poor level of personal hygiene. The presumptive presence of enteric pathogens E. coli $\mathrm{O} 157$ and Campylobacter spp. signifies the potential danger that could arise from consumption of kachumbari.

Other studies in Kenya focusing on the microbial quality of food have also observed the presence of hygiene indicators of faecal contamination, particularly in raw vegetable salads. During investigations carried out in Githurai and Gikomba markets within Nairobi County to assess the quality of street-vended foods, where kachumbari (mixture of raw tomatoes and onions) was evaluated alongside other foods, $14(14.3 \%)$ of kachumbari samples were confirmed to be positive for faecal coliforms [11]. Notable similarity of the aforementioned study and our investigation is that Salmonella spp. was not detected. Subsequent analysis of data emanating from the abovementioned study revealed significant negative association of food contamination with good hygienic practices and conducive environmental practices including washing of hands before handling food, use of an apron, availability of toilet facility with water, the presence of fresh running water in the food preparation area, and pest control [26]. A microbial quality evaluation of food served by street vendors in the industrial area Nairobi by Githaiga [12] reported high levels of total coliforms (63.6\%), Enterococci (18.2\%), and S. aureus (54.5\%) in raw and partially cooked vegetable salads $(n=11)$, but Salmonella was not detected. All vegetables samples positive for $S$. aureus exceeded the KEBS guidelines on cooked foods by harbouring $>10^{4} \mathrm{CFU} / \mathrm{g}$ [12]. However, the study did not alienate the vegetables subjected to heat treatment from raw ones. Additionally, poor personal and environmental hygiene was reported in the sampled outlets. In neighbouring Uganda, where kachumbari (fresh salad dish of tomatoes and onions) was served alongside cooked meat by $90 \%$ of pork joints in Kampala, $5.2 \%$ of tomato samples $(n=77)$ were contaminated by Salmonella enteritidis and $2.6 \%$ by Salmonella gallinarum, while onions $(n=77)$ had the presence of S. Gallinarum at 2.6\% [27].

The $\mathrm{pH}$ range, that is, $3.45-4.81$, observed during our studies did not have a strong influence on E. coli counts to a large extent in the raw salads as demonstrated by a small 
correlation coefficient $(r=+0.21)$. An assessment of raw fruit juice sold in Dares Salaam city in Tanzania, another member of the East African Community, demonstrated distinctively lower counts of E. coli and total plate counts in juices with a $\mathrm{pH}$ of $\leq 3.1$ when compared to those whose $\mathrm{pH}>3.1$ [28]. Probably, acidification of the salad resulting in a lower $\mathrm{pH}$ would have led to lower counts.

Globally and more specifically in developing countries, microbial quality evaluation of raw vegetable salads and their intact ingredients singled them out as high-risk foods. A study on the prevalence of microbial contamination on the surface of vegetables used to prepare raw salads, namely, cucumber, tomato, carrot, coriander, cabbage, beetroot, radish, and spinach (total $n=480$ ), in Dhanbad city, India, revealed $16.7 \%$ E. coli, $1.3 \%$ E. coli $\mathrm{O} 157: \mathrm{H7}$, and $4.0 \%$ Salmonella spp. contamination [29]. Assessment of salads served alongside street foods in Hyderabad, India, showed a high incidence of food-borne pathogens. In carrots $(n=53), 73.6 \%, 58.5 \%$, and $67.9 \%$ of the samples were contaminated with Staphylococcus, Salmonella, and Yersinia spp., respectively, while the corresponding incidence was $56.4 \%, 45.5 \%$, and $23.6 \%$ in onions $(n=110)$. Associated evaluation of sanitary practices revealed poor adherence to personal and environmental hygiene; $98 \%$ of the vendors did not wash the vegetables before preparation and serving, while about $56.6 \%$ of the vendors did not peel them [30]. In another recent study in Abidjan, Ivory Coast, raw mixed vegetable salad samples $(n=306)$, whose ingredients included tomatoes, onions, cucumbers, and lettuce, were seasoned or unseasoned; $100 \%, 77.8 \%$, and $2.6 \%$ were contaminated with Enterobacteriaceae, E. coli, and Salmonella, respectively. Moreover, lack of training on hygiene practices, the absence of decontamination, and crosscontamination of vegetables via contact with fresh chicken or fish were identified as the most important risk factors [31].

In the current study, we presumptively detected Campylobacter spp. in two samples obtained from the same eatery on two consecutive sampling intervals. None of the documented studies about the microbial quality of raw vegetables in Kenya had examined the occurrence of Campylobacter spp. Our quest to include it in the study was informed by isolation from chicken and beef samples from retail outlets in Nairobi [18]. Campylobacter spp. has been highlighted as a leading aetiology of bacterial enteritis $[8,9]$. Additionally, Campylobacter spp. has been found in raw vegetables. Chai et al. [32] encountered contamination of raw vegetables used in ulam, a popular Malaysian raw salad dish, from three locations which included a wet market and two supermarkets, with an average prevalence of Campylobacter spp. ranging from $29.4 \%$ to $67.7 \%$. The high levels were postulated to stem from cross-contamination with poultry products during holding at packing stages.

Increasing fruit and vegetable consumption is a priority of the World Health Organization due to its role in ameliorating incidences of micronutrient deficiencies and chronic diseases [33]. Unlike most of the fruits which can be washed and peeled, vegetables destined for raw salads including tomatoes and onions (main ingredients in kachumbari) are consumed whole upon some form of size reduction. Rendering them safe while preventing the loss of nutrients is vital. Suitable methods of preparing vegetables before consumption, for example, steaming, warrant consideration. Other techniques of surface decontamination such as use of hyperchlorinated water, chlorine dioxide, and peracetic acid normally used at the industrial scale by fresh produce companies may be too complex for food service personnel to implement. Additionally, they are usually preceded by good agricultural practices and followed by elaborate handling after sanitization to prevent postprocess contamination.

\section{Conclusions}

Our study, those of other authors, and outbreaks associated with minimally processed fresh produce warrant consideration of kachumbari for frequent microbial quality monitoring to avert food-borne illness. It affirms that hygienic practices leading to presentation of raw vegetables salads in Kenyan roast meat eateries are compromised to a large extent. This calls for intense training of food service personnel on sanitary practices. However, food safety of fresh produce is a concerted effort from field to fork, and it is rather difficult for the vendors to achieve this goal alone since they have no control over field production, transport, and marketing channels. Appropriate decontamination methods that are easy and safe to use, without adversely altering the organoleptic quality of the salads, should be applied to reduce the risk. Public health enforcement authorities ought to consider banning the sale of raw salads in establishments where microbial quality cannot be guaranteed to safeguard the consumer. Additionally, the information herein serves to caution consumers so that they can avoid being victims of food-borne infections while indulging in this popular accompaniment of roast meat. This study evaluated a limited number of salad samples as offered to the consumers in selected roast meat eateries to give a snapshot of microbial quality. The authors did not have control over numerous variables, which could have influenced the quality of the salads including the origin of raw materials, transportation, and sanitary practices during preparation. Therefore, it should not be broadly concluded that the microbial quality of kachumbari was predominantly a result of cross-contamination from meats.

\section{Data Availability}

All data arising from this study are contained within the manuscript.

\section{Conflicts of Interest}

The authors declare that there are no conflicts of interest regarding the publication of this paper.

\section{Acknowledgments}

This work was supported by the Directorate of Research, Meru University of Science and Technology. 


\section{References}

[1] Wikipedia, Kachumbari, 2017, http://en.wikipedia.org/wiki/ Kachumbari.

[2] Wikipedia, Culture of Kenya, 2017, https://en.wikipedia.org/ wiki/Culture_of_Kenya.

[3] C. L. Little and I. A. Gillespie, "Prepared salads and public health," Journal of Applied Microbiology, vol. 105, no. 6, pp. 1729-1743, 2008.

[4] M. F. Lynch, R. V. Tauxe, and C. W. Hedberg, "The growing burden of foodborne outbreaks due to contaminated fresh produce: risks and opportunities," Epidemiology and Infection, vol. 137, no. 3, pp. 307-315, 2009.

[5] European Food Safety Authority (EFSA), "Shiga toxin producing E. coli outbreak(s)," 2017, http://www.efsa.europa.eu/ en/topics/topic/ecolioutbreak2011.htm?wtrl=01.

[6] Centers for Disease Control and Prevention (CDC), "Multistate outbreak of Shiga toxin-producing Escherichia coli O157:H7 infections linked to ready-to-eat salads (final update)," 2017, https://www.cdc.gov/ecoli/2013/O157H7-11-13/ index.html.

[7] Centers for Disease Control and Prevention (CDC), "Surveillance for foodborne disease outbreaks-United States, 2008," MMWR Weekly, vol. 60, no. 35, pp. 1197-1202, 2011.

[8] L. J. Harris, J. N. Farber, L. R. Beuchat et al., "Outbreaks associated with fresh produce: incidence, growth, and survival of pathogens in fresh and fresh-cut produce," Comprehensive Reviews in Food Science and Food Safety, vol. 2, no. 1, pp. 78-141, 2003.

[9] P. Ragaert, L. Jacxsens, I. Vandekinderen, L. Baert, and F. Devlieghere, "Microbiological and safety aspects of freshcut fruits and vegetables," in Advances in Fresh-Cut Fruits and Vegetables Processing, O. M. Belloso and R. S. Fortuny, Eds., CRC Press, Boca Raton, FL, USA, 2011.

[10] J. E. O. Oloo, "Food safety and quality management in Kenya: an overview of the roles played by various stake holders," African Journal of Food Agriculture and Nutritional Development, vol. 10, no. 11, pp. 4379-4397, 2010.

[11] E. N. Kariuki, Z. W. Ng'ang'a, and P. Wanzala, "Bacteriological contamination of street foods among street food vendors in Githurai and Gikomba markets-Nairobi County, Kenya," International Journal of Innovative Research and Advanced Studies, vol. 4, no. 1, pp. 337-346, 2017.

[12] G. M. Githaiga, Microbial Quality, Strain Distribution and Enterotoxigenicity of Selected Food Borne Pathogens in Relation to the Hygienic Practices in Industrial Area, Nairobi, Kenya, M.Sc thesis, University of Nairobi, Nairobi, Kenya, 2012, http://www.uonbi.ac.ke/openscholar/john.wangoh/files/ 2012_gitahi_msc_thesis.pdf.

[13] M. Githiri, P. Okeno, and J. Kiminywe, "Hygienic practices and occurrence of coliforms and Staphylococcus on food at a public hospital in Kenya," Journal of Applied Bioscience, vol. 27, pp. 1727-1731, 2009.

[14] J. O. Oundo, S. M. Kariuki, H. I. Boga, F. W. Muli, and Y. Iijima, "High incidence of enteroaggregative Escherichia coli among food handlers in three areas of Kenya: a possible transmission route of travelers' diarrhea," Journal of Travel Medicine, vol. 15, no. 1, pp. 31-38, 2008.

[15] J. G. Kariuki and S. S. Orago, "Food handling practices and the prevalence of food borne pathogens among food handlers in Embu municipality, Kenya," International Journal of Applied Research, vol. 3, no. 1, pp. 697-698, 2017.

[16] O. K. Muinde and E. Kuria, "Hygienic and sanitary practices of vendors of street foods in Nairobi, Kenya," African Journal of Food Agriculture and Nutritional Development, vol. 5, no. 1, pp. 1-14, 2005.

[17] B. Norrung, J. K. Andersen, and S. Buncic, "Main concerns of pathogenic microorganisms in meat," in Safety of Meat and Processed Meat, F. Toldra, Ed., Springer Science+Business Media, New York, NY, USA, 2009.

[18] O. Osano and S. M. Arimi, "Retail poultry and beef as sources of Campylobacter jejuni," East African Medical Journal, vol. 76, no. 3, pp. 141-143, 1999.

[19] ISO 16649-2:2001, Microbiology of Food and Animal Feeding StuffsHorizontal Method for the Enumeration of Beta-GlucuronidasePositive Escherichia coli-Part 2: Colony-Count Technique at 44 Degrees C Using 5-Bromo-4-Chloro-3-Indolyl Beta-D-Glucuronide, ISO, Geneva, Switzerland, 2006.

[20] ISO 6888-2:1999, Microbiology of Food and Animal Feeding Stuffs-Horizontal Method for the Enumeration of CoagulasePositive Staphylococci (Staphylococcus aureus and Other Species)-Part 2: Technique Using Rabbit Plasma Fibrinogen Agar Medium, ISO, Geneva, Switzerland, 1999.

[21] ISO 6579:2002, Microbiology of Food and Animal Feeding Stuffs-Horizontal Method for the Detection of Salmonella spp., ISO, Geneva, Switzerland, 2002.

[22] ISO 16654:2001, Microbiology of Food and Animal Feeding Stuffs-Horizontal Method for the Detection of Escherichia coli O157, ISO, Geneva, Switzerland, 2001.

[23] ISO 10272-1:2006, Microbiology of Food and Animal Feeding Stuffs-Horizontal Method for Detection and Enumeration of Campylobacter spp.-Part 1: Detection Method, ISO, Geneva, Switzerland, 2006.

[24] V. C. Wu, P. Jitareerat, and D. Y. Fung, "Comparison of the Pulsifier and the Stomacher for recovering microorganisms in vegetables," Journal of Rapid Methods and Automation in Microbiology, vol. 11, no. 2, pp. 145-152, 2003.

[25] Health Protection Agency (HPA), Guidelines for Assessing the Microbiological Safety of Ready-to-Eat Foods, Health Protection Agency, London, UK, 2009, https://www.gov.uk/government/ uploads/system/uploads/attachment_data/file/363146/Guidelines_ for_assessing_the_microbiological_safety_of_ready-to-eat_foods_ on_the_market.pdf.

[26] E. N. Kariuki, Z. W. Ng'ang'a, and P. Wanzala, "Foodhandling practices and environmental factors associated with food contamination among street food vendors in Nairobi County, Kenya: a cross-sectional study," East African Health Research Journal, vol. 1, no. 1, pp. 62-71, 2017.

[27] M. Heilmann, Flies as Vectors for Salmonella spp. and Their Control in Pork Butcheries in Kampala, Uganda-A Contribution to Improve Public Health, Doctoral dissertation, Freie Universität Berlin, Berlin, Germany, 2016, http://www.diss.fuberlin.de/diss/servlets/MCRFileNodeServlet/FUDISS_derivate_ 000000020467/Heilmann_Thesis_Final.pdf;jsessionid= 18B586E6CF558C9C26347CD25E1DCA9B?hosts=.

[28] E. Simforian, H. E. Nonga, and B. K. Ndabikunze, "Assessment of microbiological quality of raw fruit juice vended in Dar es Salaam City, Tanzania," Food Control, vol. 57, pp. 302-307, 2015.

[29] S. K. Mritunjay and V. Kumar, "A study on prevalence of microbial contamination on the surface of raw salad vegetables," 3 Biotech, vol. 7, no. 1, p. 13, 2017.

[30] A. Sabbithi, R. Naveen Kumar, L. Kashinath, V. Bhaskar, and V. Sudershan Rao, "Microbiological quality of salads served along with street foods of Hyderabad, India," International Journal of Microbiology, vol. 2014, Article ID 932191, 6 pages, 2014.

[31] E. Toe, A. Dadié, E. Dako, and G. Loukou, "Bacteriological quality and risk factors for contamination of raw mixed 
vegetable salads served in collective catering in abidjan (ivory coast)," Advances in Microbiology, vol. 7, no. 6, pp. 405-419, 2017.

[32] L. C. Chai, T. Robin, U. M. Ragavan et al., "Thermophilic Campylobacter spp. in salad vegetables in Malaysia," International Journal of Food Microbiology, vol. 117, no. 1, pp. 106-111, 2007.

[33] World Health Organization (WHO), "Diet, nutrition and the prevention of chronic diseases," Tech. Rep. 916, World Health Organization, Geneva, Switzerland, 2017, http://apps.who.int/ iris/bitstream/10665/42665/1/WHO_TRS_916.pdf?ua=1. 


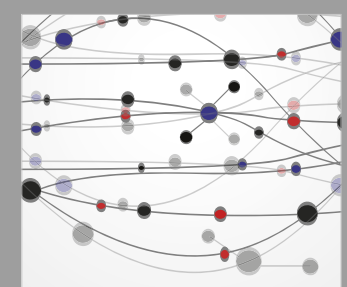

The Scientific World Journal
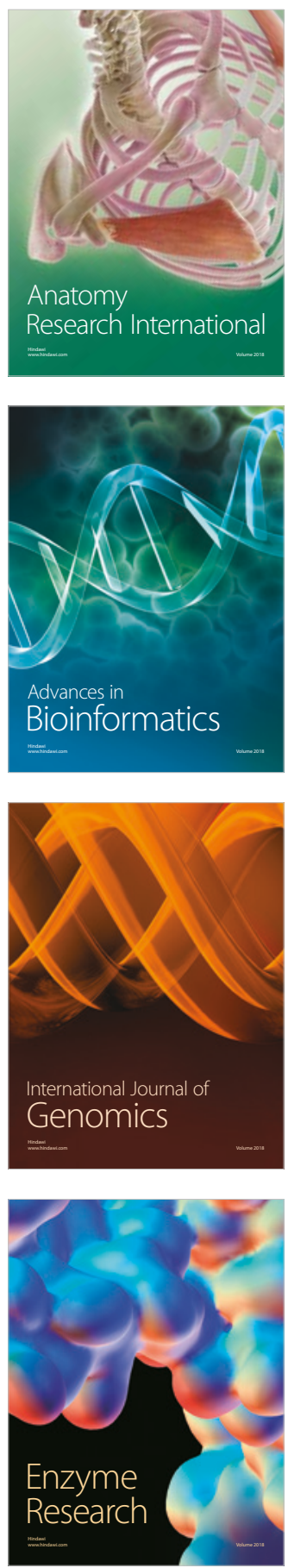
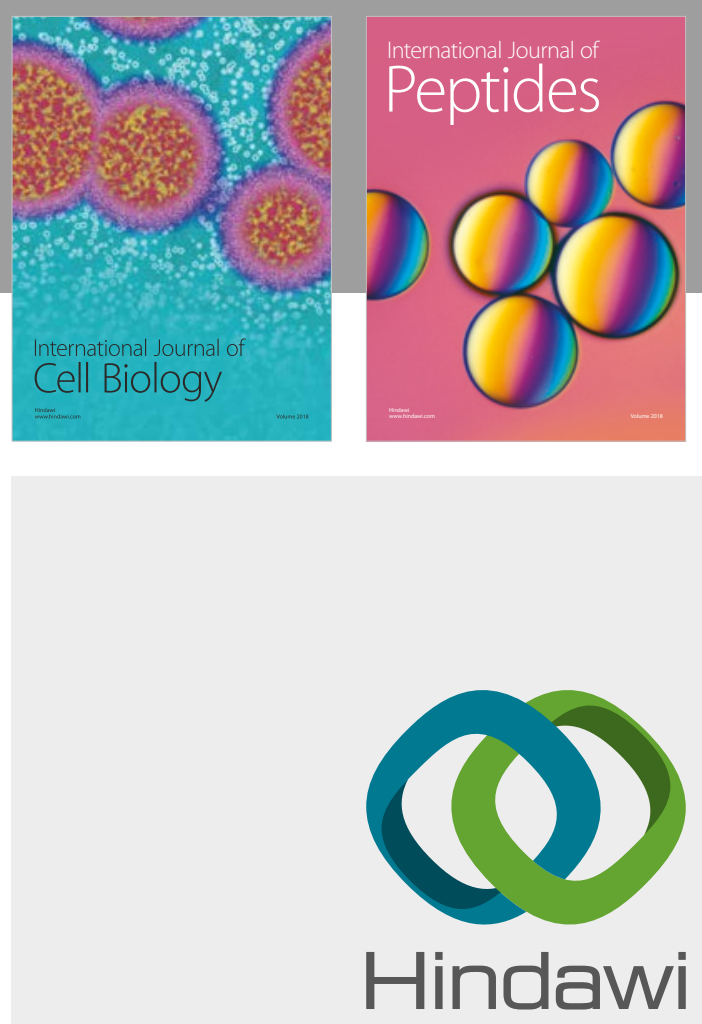

Submit your manuscripts at

www.hindawi.com
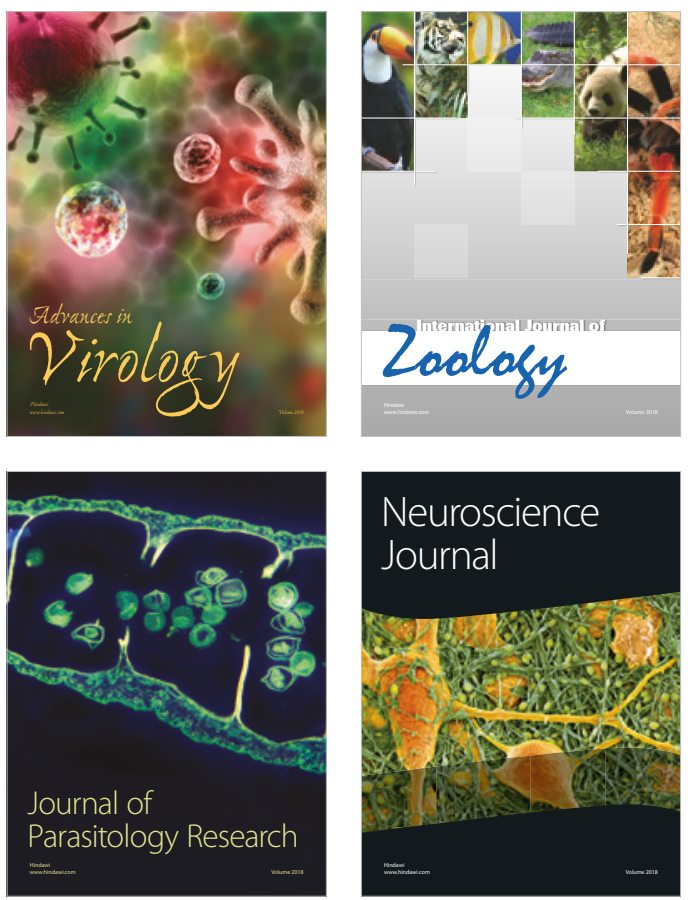
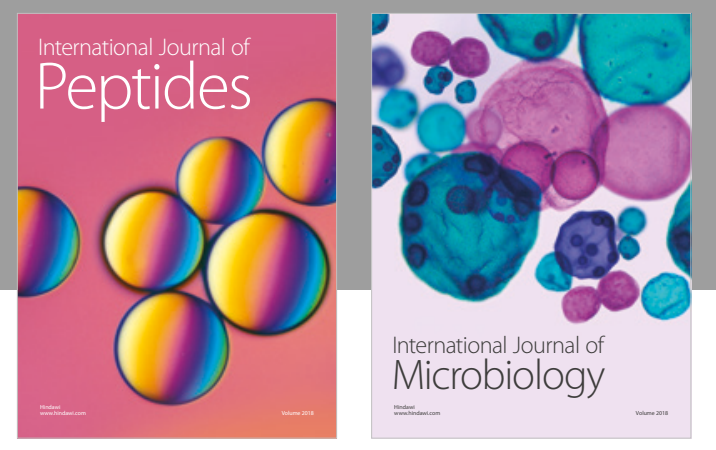

nternational Journal of Microbiology
Journal of
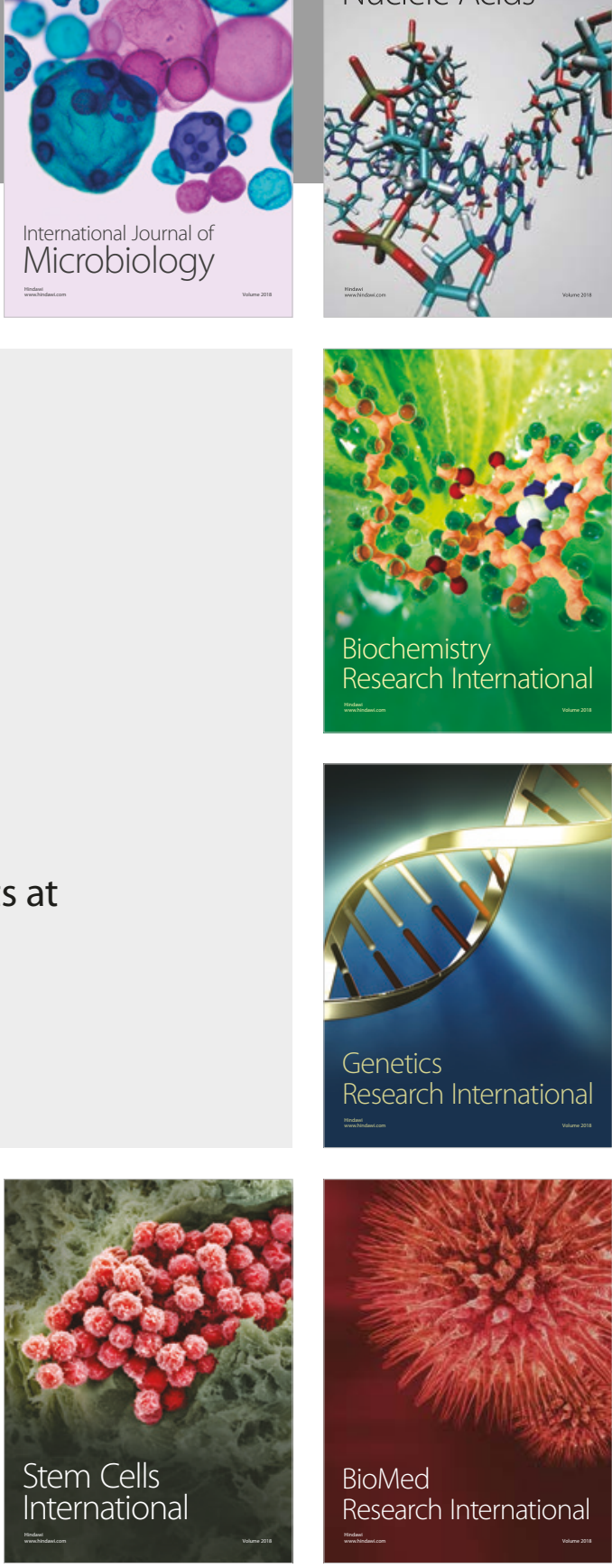
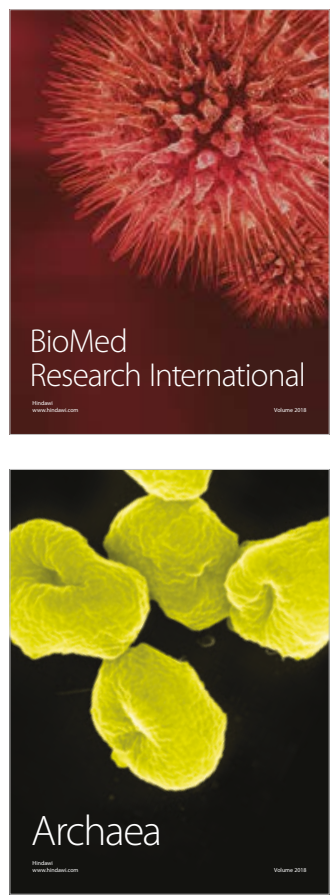